NBSIR 84-2856

\title{
Thermal Response of Unconfined Ceilings Above Growing Fires and the Importance of Convective Heat Transfer
}

U.S. DEPARTMENT OF COMMERCE National Bureau of Standards National Engineering Laboratory

Center for Fire Research

Washington, DC 20234

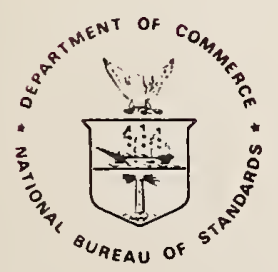

I.S. DEPARTMENT OF COMMERCE 

NBSIR 84-2856

\section{THERMAL RESPONSE OF UNCONFINED}

CEILINGS ABOVE GROWING FIRES

AND THE IMPORTANCE OF CONVECTIVE

HEAT TRANSFER

Leonard Y. Cooper

U.S. DEPARTMENT OF COMMERCE

National Bureau of Standards

National Engineering Laboratory

Center for Fire Research

Washington, DC 20234

April 1984

U.S. DEPARTMENT OF COMMERCE, Malcolm Baldrige, Secrotary NATIONAL BUREAU OF STANDARDS. Emeat Ambler. Director 

TABLE OF CONTENTS

$\underline{\text { Page }}$

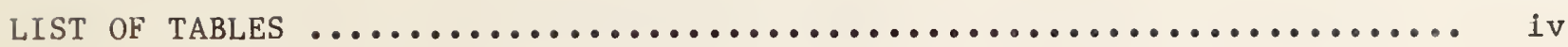

LIST OF FIGURES $\ldots \ldots \ldots \ldots \ldots \ldots \ldots \ldots \ldots \ldots \ldots \ldots \ldots \ldots \ldots \ldots \ldots \ldots \ldots \ldots \ldots \ldots \ldots \ldots \ldots$

Abstract $\ldots \ldots \ldots \ldots \ldots \ldots \ldots \ldots \ldots \ldots \ldots \ldots \ldots \ldots \ldots \ldots \ldots \ldots \ldots \ldots \ldots \ldots \ldots \ldots \ldots \ldots$

1. InTRODUCTION $\ldots \ldots \ldots \ldots \ldots \ldots \ldots \ldots \ldots \ldots \ldots \ldots \ldots \ldots \ldots \ldots \ldots \ldots \ldots \ldots \ldots \ldots \ldots \ldots \ldots . \ldots \ldots$

2. THE MODEL FOR THE CEILING RESPONSE ....................... 3

2.l Heat Transfer at the Lower Ceiling Surface ................ 4

2.2 Heat Transfer from the Upper Ceiling Surface ............... 6

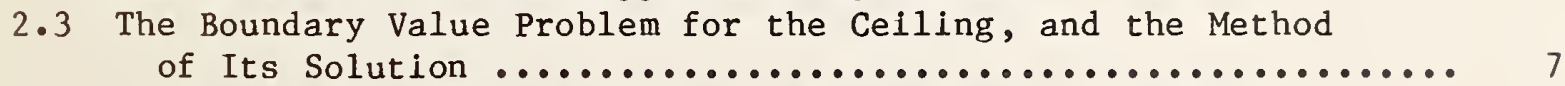

2.4 Convective Heat Transfer from the Plume Gases - Enthalpy

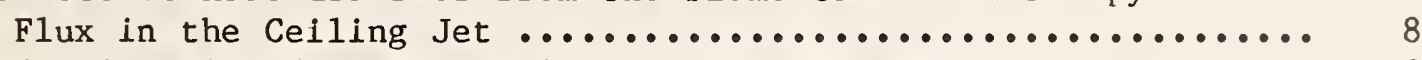

2.5 Radiative Flux from the Ceiling to Lower Targets ............ 9

3. CALCULATIONS FOR THE RESPONSE OF A VARIETY OF DIFFERENT CEILING CONSTRUCTIONS TO DIFFERENT FIRE THREATS .................... 10

3.1 Descriptions of the Ceiling Constructions and Fire Threats ..... 10

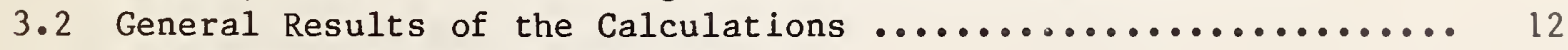

3.3 Discussion of Overall Results ......................... 12

4. ON THE IMPORTANCE OF CONVECTIVE HEAT TRANSFER ................. 13

4.1 Predicting Ceiling Temperatures .......................... 14

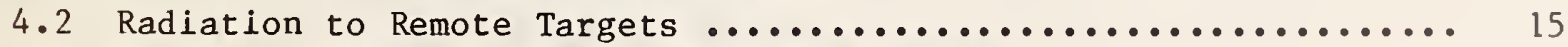

4.3 Net Heat Transfer from the Enclosure Gases ................ 17

5. SUMMARY OF CONCLUSIONS AND FUTURE WORK ................... 18

6. ACKNOWLEDGMENTS ....................................... 20

7. REFERENCES ......................................... 20

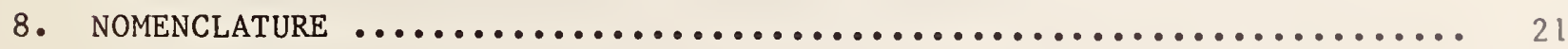




\section{LIST OF TABLES}

Page

Table 1. Description of the four ceiling constructions ............. 23

Table 2. Description of the six fire scenarios .................... 24 


\section{LIST OF FIGURES}

$\underline{\text { Page }}$

Figure 1. The unconfined celling fire scenario.

Figure 2. Responses of different ceiling constructions of Table 1 (insulation board , gypsum board ...., concrete ---, steel__.._ to fire scenarios of Table 2.
(a) $\mathrm{Q}, \mathrm{H}=10 \mathrm{l} \cdot 2 \mathrm{~kW}, 2 \mathrm{~m}$;
(b) $Q, H=1000 \mathrm{~kW}, 2 \mathrm{~m}$;
(c) $Q, H=1000 \mathrm{~kW}, 5 \mathrm{~m}$;
(d) $\mathrm{Q}, \mathrm{H}=9883 \mathrm{~kW}, 5 \mathrm{~m}$; (e) $\mathrm{Q}, \mathrm{H}=0.1054 \mathrm{t}^{2} \mathrm{~kW}, 2 \mathrm{~m}$;
(f) $Q, H=0.1054 t^{2} \mathrm{~kW}, 5 \mathrm{~m}$ ( $\mathrm{t}$ in seconds)

Figure 3. Plot of $q_{\text {conv, } L}(r=0, t) / q_{L}^{\prime \prime}(r=0, t)$ for different ceiling constructions of Table 1 (see legend of Figure 2) to the fire scenario $\mathrm{Q}, \mathrm{H}=0.1054 \mathrm{t}^{2} \mathrm{~kW}, 2 \mathrm{~m}$ ( $\mathrm{t}$ in seconds) ........ 28

Figure 4. Plot of $T_{S, L}(r=0, t)-T_{a m b}$ for different ceiling constructions of Table 1 (see legend of Figure 2) to the fire scenario $\mathrm{Q}, \mathrm{H}=0.1054 \mathrm{t}^{2} \mathrm{~kW}, 2 \mathrm{~m}$ with $\mathrm{q}_{\mathrm{conv}, \mathrm{L}}^{\prime \prime}=0$ ( $\mathrm{t}$ in seconds) $\ldots \ldots \ldots \ldots \ldots$

Figure 5. Plots of radiant flux to remote targets from the gypsum board celling responding to the fire scenario $Q, H=0.1054 t^{2} \mathrm{~kW}, 2 \mathrm{~m}$; nonzero $\mathrm{q}_{\text {conv }, \mathrm{L}} \ldots, \mathrm{q}_{\text {conv }, \mathrm{L}}=0 \ldots \ldots$ ( $\mathrm{t}$ in seconds $) \ldots \ldots \ldots$ 

THERMAL RESPONSE OF UNCONFINED CEILINGS ABOVE GROWING FIRES AND THE IMPORTANCE OF CONVECTIVE HEAT TRANSFER

\author{
Leonard Y. Cooper \\ National Bureau of Standards \\ Washington, DC 20234
}

\title{
Abstract
}

A procedure is developed to calculate the thermal response of unconfined non-burning cellings above growing fires. The procedure uses an algorithm for conduction into the celling material. It takes account of heat transfer due to radiation from the combustion zone to the ceiling surface, and due to reradiation from the celling to the floor and furnishings. Finally, the procedure uses a previously developed algorithm for convective heat transfer to the celling from the fire-plume-driven ceiling jet. The procedure is used to predict radialdependent surface temperature histories of typical ceiling materials under a variety of different realistic levels of hazardous fire energy generation rates and combustion zone-celling separation distances. The results give an indication of the influence of convective heat transfer on peak ceiling thermal response, losses from fire plume gases, and radial variations and peak values of celling-to-floor irradiation during enclosure fires. 
Key words: ceilings, compartment fires, fire plumes, heat transfer, room fires.

\section{INTRODUCTION}

In reference [1] an algorithm was developed to estimate the radial- and time-dependent convective heat transfer to unconfined ceilings above growing fires. Together with an account of radial-dependent radiant heat transfer to and from the ceiling, it would appear that such an algorithm is required to predict the thermal response of the ceiling material from the time of fire initiation (when the ceiling and lower gas temperature is at a uniform ambient temperature, $\mathrm{T}_{\mathrm{amb}}$ ), to critical times during the course of hazardous fires (when the temperature field of the ceiling material can have significant variation in both thickness and radial position, $r$, from the ceiling-fire plume impingement point). Examples of such critical times might be those times when near-ceiling fire detectors and/or fusible sprinkler links are actuated, when the ceiling surface reaches an ignition or failure temperature, and when radiation from the ceiling to occupants or combustible furnishings below, reaches critical levels.

The importance of position-dependent ceiling response, to an understanding of hazardous fire phenomena, in general, does not appear to have been previously studied. To do so is a major objective of this work.

As pointed out in [1], at relatively early times subsequent to the ignition of a fire the unconfined ceiling fire scenario depicted in figure 1 
is relevant to enclosure fire scenarios where celling surfaces are inherently confined. Also, as discussed in [2] and [3], even at later times during enclosure fires when the inevitable upper layer of elevated temperature gases has partially filled the enclosure, analytic methods for describing the unconfined celling fire scenario can still be directly used to predict continuing changes in the fire-generated enclosure response.

This work represents the first stage of an investigation of the response of real ceiling materials above typical hazardous fires. This first stage effort deals with the response of ceilings in the unconfined ceiling fire scenario. Subsequent stages will use the present procedures together with the ideas of [2] and [3] to study confined celling, enclosure fire scenarios.

\section{THE MODEL FOR THE CEILING RESPONSE}

Figure $l$ is a sketch of the fire scenario under consideration. A fire, modeled as a point source of total time-dependent energy release rate $Q(t)$, is initiated a distance $\mathrm{H}$ below an expansive (unconfined) ceiling. Because of their elevated temperature the products of combustion of the fire are driven upwards by buoyancy. These products generate a turbulent plume of upward moving, elevated temperature gases. The fraction of $Q$ which effectively acts to heat the plume gases and drive the plume's upward momentum is taken to be $l-\lambda_{r}$, where $\lambda_{r}$ is approximately the fraction of $Q$ lost by radiation from the combustion zone. 


\subsection{Heat Transfer at the Lower Celling Surface}

As indicated in figure 1 , the radiant energy, $\lambda_{r} Q$, is assumed to be radiated uniformly outward from the fire. The radiant flux, q" incldent on the lower surface of the celling at a distance $r$ from the plumeceiling impingement point is, therefore,

$$
\mathrm{q}_{\mathrm{rad}-\mathrm{fire}}^{\prime \prime}=\left[\lambda_{\mathrm{r}} \mathrm{Q} /\left(4 \pi \mathrm{H}^{2}\right)\right]\left[1+(\mathrm{r} / \mathrm{H})^{2}\right]^{-3 / 2}
$$

The fire plume gases continue to rise and entrain air from the amblent environment. When their upward movement is blocked by the celling, they spread radially outward forming a relatively thin, turbulent, ceiling jet.

As was done in eq. (1), radlation absorption and emission of the celling jet will be neglected throughout this paper. In the case of the early time, unconfined celling, fire scenario under consideration, this neglect is justified, for example, if one anticlpates effectlve celling jet thicknesses of the order of a few tenths of a meter and absorption coefficients of the order of a few tenths of an inverse meter.

Heat is transferred by convection from the ceiling jet to the lower surface of the ceiling. At an arbitrary time after ignition, this radialdependent heat flux, q" conv,L, can be estimated from [1]

$$
q_{\text {conv, } L}^{\prime \prime}=h_{L}\left(T_{\text {ad }}-T_{s, L}\right)
$$


where $T_{S, L}$ is the then-current, absolute temperature of the lower surface of the celling, and $\mathrm{T}_{\text {ad }}$ is the temperature of the gas that would be measured adjacent to the lower celling surface under the condition of an adlabatic celling. $h_{L}$ and $T_{a d}$ of eq. (2) can be estimated [1] from

$$
\begin{aligned}
& \mathrm{h}_{\mathrm{L}} / \tilde{\mathrm{h}}=\left\{\begin{array}{l}
7.75 \mathrm{Re}^{-0.5}[\mathrm{l}-(\mathrm{r} / \mathrm{H})(5 .-0.390 \mathrm{Re} \\
0.213 \mathrm{Re}^{-0.3}(\mathrm{r} / \mathrm{H})^{-0.65}, 0.2 \leq \mathrm{r} / \mathrm{H} \leq 1.03 \\
0.217 \operatorname{Re}^{-0.3}(\mathrm{r} / \mathrm{H})^{-1 / 2}, 1.03 \leq \mathrm{r} / \mathrm{H}
\end{array}\right. \\
& \frac{\left(\mathrm{T}_{\text {ad }}-\mathrm{T}_{\text {amb }}\right)}{\mathrm{T}_{\text {amb }} \mathrm{Q}_{\mathrm{H}}^{2 / 3}}= \begin{cases}10.22 \exp (-1.77 \mathrm{r} / \mathrm{H}), 0 \leq \mathrm{r} / \mathrm{H} \leq 0.750 \\
2.10(\mathrm{r} / \mathrm{H})^{-0.88}, 0.750 \leq \mathrm{r} / \mathrm{H}\end{cases}
\end{aligned}
$$

where

$$
\begin{aligned}
\tilde{h} & =\rho_{a m b} C_{p} g^{1 / 2} \mathrm{H}^{1 / 2}{ }_{\mathrm{Q}_{\mathrm{H}}^{*}}^{1 / 3} ; \operatorname{Re}=\mathrm{g}^{1 / 2} \mathrm{H}^{3 / 2} \mathrm{Q}_{\mathrm{H}}^{*}{ }^{1 / 3} / \nu_{\mathrm{amb}} ; \\
\mathrm{Q}_{\mathrm{H}}^{*} & =\left(1-\lambda_{\mathrm{r}}\right) \mathrm{Q} /\left[\rho_{\mathrm{amb}}{ }_{\mathrm{p}} \mathrm{T}_{\mathrm{amb}}(\mathrm{gH})^{1 / 2} \mathrm{H}^{2}\right]
\end{aligned}
$$

and where $\rho_{a m b}, C_{p}$ and $\nu_{a m b}$ are the density, specific heat, and kinematic viscosity of the amblent air. In the above, $\mathrm{Q}_{\mathrm{H}}^{*}$ is a dimensionless number representing the relative strength of the fire, and $\operatorname{Re}$ is a characteristic Reynold's number of the fire plume at the elevation of celling implngement.

As time goes on, $\mathrm{T}_{S, L}$, initially at $\mathrm{T}_{\mathrm{amb}}$, begins to increase. At al1 times this surface is assumed to diffusely radlate to the inltially amblent temperature, expanslve, lower floor surface and to exposed surfaces of furniture or other 1 tems. In response to this radlation the temperatures of these surfaces also Increase with time. For times of interest here, it is assumed that these "floor" temperature increases are always relatively small compared to the characteristic increases of $T_{S, L}$. Accordingly, at a given radial 
position of the lower ceiling surface, the net radiation exchange between the ceiling and the floor/furniture/etc. surfaces below can be approximated by a net reradiation flux

$$
\mathrm{q}_{\mathrm{rerad}, \mathrm{L}}^{\prime \prime}=\varepsilon_{\mathrm{L}} \sigma\left(\mathrm{T}_{\mathrm{s}, \mathrm{L}}^{4}-\mathrm{T}_{\mathrm{amb}}^{4}\right)
$$

where $\sigma$ is the Stephan-Boltzmann constant and $\varepsilon_{L}$ is the emittance/ absorptance of the assumed grey, lower ceiling surface.

\subsection{Heat Transfer from the Upper Celling Surface}

Heat is transferred through the ceiling, and eventually the temperature of its upper surface, which is also assumed to be exposed to a constant $T_{a m b}$ environment, begins to rise.

The rate of heat transfer from the upper surface has convective and radiative components, $\mathrm{q}_{\text {conv, } U}$ and $\mathrm{q}_{\text {rerad, } U}$, respectively, which can be est $1-$ mated from

$$
\mathrm{q}_{\text {conv }, U}=h_{U}\left(T_{s, U}-T_{a m b}\right) ; q_{\text {rerad }, U}=\varepsilon_{U} \sigma\left(T_{s, U}^{4}-T_{a m b}^{4}\right)
$$

where $T_{S, U}$ is the instantaneous, radius-dependent upper surface temperature, $h_{U}$ is an effective heat transfer coefficient, and $\varepsilon_{U}$ is the emittance/ absorptance of the assumed grey, upper ceiling surface. The value for $h_{U}$ to be used in the present calculations, will be [4]

$$
h_{U}=1.675\left|T_{s, U}-T_{a m b}\right|^{l / 3} \mathrm{~W} / \mathrm{m}^{2}\left(T \text { in }{ }^{0} \mathrm{~K}\right)
$$


2.3 The Boundary Value Problem for the Ceiling, and the Method of Its Solution

The absolute temperature field, $T(r, t)$, in the celling material is assumed to be governed by the Fourler heat conduction equation. Initially, the ceiling is taken to be of uniform temperature, $T_{\text {amb }}$. The rates of heat transfer to the lower and upper surfaces, $\mathrm{q}_{\mathrm{L}}^{\prime \prime}$ and $\mathrm{q}_{\mathrm{U}}^{\prime \prime}$, respectively, are given by

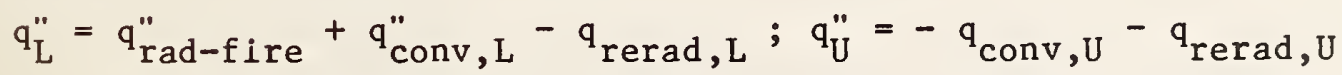

For times of interest here, radial gradients of variables of the problem are assumed to be small enough so that conduction in the ceiling is quasi-one dimensional in space, $i . e ., T=T(Z, t ; r)$, where $Z$ is the Indepth celling coordinate.

An algorithm for solving the above problem was developed. $Q, \lambda_{r}, H$, properties of the amblent environment, celling thickness and material properties are specified along with the position of radial locations of interest. The solution to the heat conduction equation for the ceiling at every specified radial position is by finite differences. The algorithm for this was taken from [5] and [6]. For a given calculation, $N \leq 20$ equally spaced points are positioned at the surfaces and through the thickness of the celling. The spacing, $\delta Z$, is selected to be large enough (based on a maximum time step) to insure stability of the calculation. Throughout a calculation, time steps are made small enough so that, at a given lower surface node, the temperature increase for each time step never exceeds one percent of the then current value of $\mathrm{T}$ at that node. 


\subsection{Convective Heat Transfer from the Plume Gases -} Enthalpy Flux in the Ceiling Jet

A key parameter in enclosure fire modeling is the net rate of heat transfer from the plume-ceiling jet gases to the enclosure boundaries. The value of this can play a very important role in a determination of the temperature history of the upper "smoke" layer of enclosure fires. For the unconfined ceiling scenario, one anticipates that convection dominates this heat transfer and, as mentioned earlier, that it is reasonable to neglect radiative transfer to and from the relatively thin ceiling jet.

The rate of convective heat transfer to the lower ceiling surface out to radius $r$ will be expressed as a fraction, $\lambda_{\text {conv, }}$ of $Q$ according to

$$
\lambda_{\text {conv }}(r, t) Q(t)=2 \pi \int_{0}^{r} q_{\text {conv }, L}(r, t) r d r
$$

Thus, of the total instantaneous energy release rate, $Q$, of the fire, $\lambda_{r} Q$ is lost to bounding surfaces of the enclosure by radiation from the combustion zone and, within a circle of radius $r, \lambda_{\text {conv }} Q$ is lost by convection from the ceiling jet.

At a given radius, the total enthalpy flux of the ceiling jet is $\left(1-\lambda_{r}-\lambda_{\text {conv }}\right)$ Q. A reliable estimate for the enthalpy flux of these diluted products of combustion is required in enclosure fire modeling since these are the ceiling jet gases which, when eventually blocked by a vertical wall, will be turned back to develop into the potentially hazardous upper smoke layer. 
In the present calculations the value of $\lambda_{\text {conv }}$ at an arbitrary value of $r$ is obtained as follows:

At a given instant of time in the calculation, $q^{\prime \prime}$ conv, $L$ is approximated by a piecewise linear function of $r$ which passes through the $\mathrm{q}^{\prime \prime}$ conv, $\mathrm{L}$ values previously computed at the selected radial positions. This function is then integrated according to eq. (10) to yield $\lambda_{\text {conv }}$ as a plecewise quadratic function of $r$.

\subsection{Radiative Flux from the Ceiling to Lower Targets}

One measure of the hazard of an enclosure fire is the radiative flux to nonburning combustible target items. The main concern is the onset of remote ignitions which could rapidly lead to flashover. Radiation from the combustion zone contributes to the remote target flux, but even for items shielded from direct fire radiation, illumination from lower ceiling surface radiation alone can lead to flashover. This latter radiative flux will decrease with distance from the fire and will vary with the orientation of the target surface.

The present algorithm includes a capability for calculating downward radiative flux from the ceiling to horizontal target surfaces. This is obtained with the use of the commonly available view factor between a disc (and, from this, an annulus), and a parallel but otherwise arbltrarily pos 1tioned target surface element. At a given instant of time in a calculation, this view factor is used to compute the total ceiling-to-target radiant flux as follows : 
The ceiling is divided into a disc (center at the plume impingement point) of radius $0.1 \mathrm{H}$, and 99 concentric, contiguous annuli of ring width $0.1 \mathrm{H}$. The temperature of the disc and of each annulus is assumed uniform at the position of its average radius, at which location the temperature is estimated from linear interpolations between previously computed, current ceiling temperatures. Appropriate view factors are used, and the radiative flux from the disc and from each annulus to the target location of interest is computed and summed sequentially starting from the plume axis. The summation is stopped when the flux contribution of an annulus is less than one percent of the largest of the previous single annuli contributions at the current time step. If the latter condition is still not achieved by the outermost annulus ( $1 . e^{.}$, at $r / H=10$. ), then the entire calculation for that target location is assumed to be invalid. In this calculation, a black body lower ceiling surface is assumed.

3. CALCULATIONS FOR THE RESPONSE OF A VARIETY OF DIFFERENT CEILING CONSTRUCTIONS TO DIFFERENT FIRE THREATS

3.l Descriptions of the Celling Constructions and Fire Threats

The algorithm described in the last section was exercised for fire scenarios involving four typical ceiling constructions identified by ceiling material and thickness in table 1 , and six fire scenarios identified by the $x^{\prime}$ ed pairs of $Q$ and $H$ in table 2. The response of each of the ceiling constructions to each of the fire scenarios was calculated. Each of these 24 calculations was carried out to $300 \mathrm{~s}$, or was terminated if the peak ceiling 
temperature at $\mathrm{r}=0$ exceeded $1300^{\circ} \mathrm{K}$. In all calculations $\mathrm{T}_{\mathrm{amb}}$, $\rho_{\mathrm{amb}}, \mathrm{C}_{\mathrm{p}}$, and $\nu_{\text {amb }}$ were taken as $300^{\circ} \mathrm{K}, 1.177 \mathrm{~kg} / \mathrm{m}^{3}, 1004 . \mathrm{Ws} /\left(\mathrm{kg}^{\circ} \mathrm{K}\right)$ and $0.1568\left(10^{-4}\right) \mathrm{m}^{2} / \mathrm{s}$, respectively; $\varepsilon_{U}=\varepsilon_{L}=1$ (black body surfaces); and $\lambda_{r}=0.35$. This latter value for $\lambda_{r}$ is a reasonable choice for typical hazardous, flaming fires [7]. The celling response was computed at 28 values of $r$, where the $r / H$ for these were $\mathrm{r} / \mathrm{H}=0 ., 0.1,0.2,0.3,0.4,0.5,0.6,0.7,0.8,0.9,1.0,1.25,1.50,1.75$, $2.00,2.25,2.50,2.75,3.00,3.5,4.0,4.5,5.0,6.0,7.0,8.0,9.0,10.0$.

The fire scenarios of table 2 involve the two fire-to-ceiling distances $2 \mathrm{~m}$ and $5 \mathrm{~m}$, and four different $\mathrm{Q}^{\prime} \mathrm{s}$. $\mathrm{H}=2 \mathrm{~m}$ would relate, say, to slightly elevated fires in residential-type occupancies, where a typical floor-tocelling helght is $2.4 \mathrm{~m}$. $\mathrm{H}=5 \mathrm{~m}$ relates to fires in larger spaces such as places of assembly or commercial storerooms.

Besides the Q,H pair which defines a given fire scenario, the corresponding value of $\mathrm{Q}_{\mathrm{H}}^{*}$ is also displayed in table 2. Note that the "odd" values $\mathrm{Q}=101.2 \mathrm{~kW}$ at $\mathrm{H}=2 \mathrm{~m}$ and $9883 \mathrm{~kW}$ at $\mathrm{H}=5 \mathrm{~m}$ were chosen to exact $1 \mathrm{y}$ reproduce the two Q values of 0.01048 and 0.1035 , which correspond to the $1000 \mathrm{~kW}$ fires of $\mathrm{H}=5 \mathrm{~m}$ and $\mathrm{H}=2 \mathrm{~m}$, respectively. Thus, for example, effects of a dimensionless $\mathrm{Q}_{\mathrm{H}}^{*}=0.01048$ fire strength is predicted here for two dramatically different physical fire scenarios.

of the different $Q^{\prime} \mathrm{s}$, the $101.2 \mathrm{~kW}$ level is characteristic of fires in small chairs or large wastepaper baskets; the $1000 \mathrm{~kW}$ level is characteristic of peak levels of fires in bedding or in upholstered couches; and the $9883 . \mathrm{kW}$ level is characteristic of a $1-1.5 \mathrm{~m}^{2}$ fuel spill fire, or of peak levels of fires in a variety of typical arrangements of stacked commodities, as identi- 
fied in table 4.1 of [8]. Finally, as identified in table 4.2 of [8], the $t^{2}$ fire of table 2 is characteristic of the growth stages of fires in various diverse arrangements of combustibles, e.g., wood pallets stacked $3 \mathrm{~m}$ high.

\subsection{General Results of the Calculations}

Some results of the aforementioned calculations are presented in figure (groups) 2a-f. Each one of the six figure groups are associated with the ceiling responses to one of the six fire threats. Plots of three of the several variables of the ceiling responses, which were obtained during the course of a calculation, are presented in each figure group, one variable for each figure of the group. The left-hand figures present plots of the peak ceiling temperature increase $T_{S, L}(r=0, t)-T_{a m b}$ vs $t$. The center figures present plots of the radial distribution of the normalized T ${ }_{s, L}$ 's, $\left[\mathrm{T}_{s, L}(\mathrm{r}, \mathrm{t})-\mathrm{T}_{\mathrm{amb}}\right] /\left[\mathrm{T}_{\mathrm{s}, \mathrm{L}}(\mathrm{r}=0, \mathrm{t})-\mathrm{T}_{\mathrm{amb}}\right]$, for $\mathrm{t}=10 \mathrm{~s}$ and $300 \mathrm{~s}$. The right-hand figures present plots of $\lambda_{\text {conv }}(r, t)$, also for 10 s and 300 s.

\subsection{Discussion of Overall Results}

The results of figures $2 \mathrm{a}-\mathrm{f}$ provide insight into the early time response of real and significantly different ceiling constructions to typical hazardous fires developing in expansive enclosure geometries. Within the specific limitations discussed above, the computation algorithm can be used to estimate the response of any other non-burning ceiling construction to arbitrarily specified $H, Q$ combinations. 
Results for the two pairs of identical Q* fire scenarios can be compared in figures $2 \mathrm{a}$ and $2 \mathrm{c}\left(\mathrm{Q}^{*}=0.01048\right)$ and in figures $2 \mathrm{~b}$ and $2 \mathrm{~d}\left(\mathrm{Q}_{\mathrm{H}}^{*}=0.1035\right)$. Considering the significant differences in the values of $Q$ and $H$, the lower ceiling surface temperature responses (i.e., the left and center figures) for a given $Q^{*}$ are remarkably similar. This is especlally true for the $r=0$ temperature histories. Thus, it appears that for constant $Q$ fires, and for a fairly wide range of $\mathrm{H}$ values, it may be possible to describe the unconfined ceiling impingement point temperature response with reasonable accuracy by specifying $\mathrm{Q}^{*}$ alone instead of the $\mathrm{Q}, \mathrm{H}$ ( or $\mathrm{Q}_{\mathrm{H}}^{*}, \mathrm{H}$ ) pair.

The response of the ceilings is strongly influenced by the characteristic dimension $\mathrm{H}$ of the enclosure fire problem. Thus, the center plots of figures 2 indicate significant variation of $T_{S, L}$ with $r / H$ variations of the order of 1. When attempting to model enclosure fire environments, this suggests that calculations of the celling response in terms of a simple spatial average may not be adequate.

4. ON THE IMPORTANCE OF CONVECTIVE HEAT TRANSFER

The significant impact of radiation heat transfer on enclosure fire environments is well known. The corresponding importance of convective heat transfer, however, is not clear and enclosure fire models have taken this effect into account in only the most rudimentary manner. 


\subsection{Predicting Ceiling Temperatures}

The importance of ceiling surface temperatures to fire hazard analyses is mentioned in the introduction. The present calculations indicate that, in general, lower ceiling surface convective heat transfer is significant in the sense that reliable estimates of its values are required if such temperature predictions are to be made with reasonable accuracy.

To illustrate this, plots of $\mathrm{q}_{\text {conv, }}(\mathrm{r}=0, \mathrm{t}) / \mathrm{q}_{\mathrm{L}}^{\prime \prime}(\mathrm{r}=0, \mathrm{t})$ are presented in figure 3 for the previously calculated $2 \mathrm{~m}, Q \sim \mathrm{t}^{2}$ fire scenario. The result is typical of that of the other fire scenarios considered here, in that at all times considered, $q_{\text {conv }, L}(r, t)$ at $r=0$ (and, indeed, at all $r$ ) is generally of the order of $q_{L}^{\prime \prime}(r, t)$.

To further illustrate the significance of $\mathrm{q}_{\text {conv, }}$ on $\mathrm{T}_{\mathrm{S}, \mathrm{L}}$, the ceiling responses to the $2 \mathrm{~m}, Q \sim t^{2}$ fire scenario was calculated a second time under a condition of $\mathrm{q}_{\text {conv, }}=0$. The results for $\mathrm{T}_{S, L}(\mathrm{r}=0, \mathrm{t})-\mathrm{T}_{\text {amb }}$ are plotted in figure 4, which is to be compared to the left-hand plots of figures 2e. For example, consider a papered gypsum board celling with an ignition temperature of $700^{\circ} \mathrm{K}$. Then, for the $2 \mathrm{~m}, \mathrm{Q \sim t^{2 }}$ fire scenario, the left-hand gypsum board plot of figure $2 \mathrm{e}$ indicates that ignition of the ceiling will occur at approximately 120 s while the calculations of figure 4, which neglect convection, indicate that ignition will occur at 190 s. 


\subsection{Radiation to Remote Targets}

Another key to successful fire hazard analysis is prediction of the ignition of target surfaces removed from the immediate vicinity of a fire's combustion zone. Such ignition would typically occur on account of radiant fluxes from the hot ceiling surface, from the upper hot smoke layer, and from the flame itself.

Depending on target orientation and elevation, direct flame radiation, which diminishes inversely as the square of the distance from the combustion zone, could be significant for targets close to the fire. This component of radiant flux to remote targets will not be considered here.

At early times during enclosure fires when smoke layer accumulations are still not significant and when the present type of unconfined ceiling calculations are directly applicable, radiation from these layers will be negligible. Even when smoke layer thicknesses become a significant fraction of $H$, they can still be optically thin to the extent that gas radiation to remote target surfaces will not be significant. Under the two latter circumstances (at least), and at targets sufficiently removed from walls, overhead radiation will be determined by the temperature distribution of the lower celling surface.

In predicting remote ignition of targets under expansive cellings, the fact that ceiling temperature distributions are distinctly nonuniform is key. Thus, one expects that the peak value of $T_{S, L}$ at $r=0$, as well as 1 ts $r$ distribution is important in establishing the levels of remote target lrradla- 
tion. Also, one anticipates that significant reductions of $T_{S, L}$ with $r$, suggested in the center plots of figure 2, lead to a significantly reduced threat of remote ignition far from the fire.

Based on these observations and on earlier remarks, it would appear that the radial dependence of convective heat transfer to the lower ceiling surface can play an important role in predicting remote ignition/flashover threats during enclosure fires.

To illustrate this conclusion quantitatively, the overhead radiant flux to horizontal remote targets a distance $\mathrm{H}$ below the gypsum board ceiling is plotted vs $\mathrm{r} / \mathrm{H}$ and at different times in figure 5 for the $2 \mathrm{~m}, \mathrm{Q} \sim \mathrm{t}^{2}$ fire. These fluxes were obtained using the $T_{S, L}$ presented in the left and center plots of figure $2 e$, and the target radiation calculation scheme described earlier. For comparison, the radiation flux for the same ceiling construction and fire, but $q_{\text {conv, }}=0$ ( $i . e .$, corresponding to the gypsum $T_{S, L}$ of figure 4 ), is also plotted in figure 5 .

As can be seen in figure 5, there is a significant reduction of overhead flux to targets which are removed distances of the order of $\mathrm{H}$ from the fire. Also, neglect of convection appears to lead to serious underestimates of peak fluxes when they reach typical hazardous levels of $2 \mathrm{~W} / \mathrm{cm}^{2}$ and above. For example, at $300 \mathrm{~s}$, the peak predicted flux level of $3.67 \mathrm{~W} / \mathrm{cm}^{2}$ is reduced to 67 percent of its value $\left(2.44 \mathrm{~W} / \mathrm{cm}^{2}\right)$ if convection is neglected. 


\subsection{Net Heat Transfer from the Enclosure Gases}

When $\lambda_{\text {conv }}$ is a significant fraction of $1-\lambda_{r}$ (which, as assumed here, is typically equal to 0.65 ) then the net rate of heat transfer from the enclosure gases to ceilings would definitely be required to predict temperature histories of enclosure fire environments. However, if $\lambda_{\text {conv }}$ is relatively sma11, then such heat transfer estimates may not be important.

The right-hand plots of figure 2 indicate that $\lambda_{\text {conv }}$ is of the order of 0.1 or less for small to moderate $\mathrm{r} / \mathrm{H}$. Except for very early times, this is also true for larger $\mathrm{r} / \mathrm{H}$. For the purposes of estimating net enthalpy flux in the celling jet this would seem to suggest that accurate estimates of the convective loss to the ceiling may not be critical in the calculation of average, enclosure smoke layer temperatures. Careful scrutiny of the situation does not, however, provide any real confidence in such a conclusion:

For early times, when the present unconfined-celling-type of calculation hopefully provides reliable estimates of ceiling response, modeling of fire growth is key. In this regard early time celling responses to the $Q \sim t^{2}$ fires of figures $2 e$ and $f$ are particularly relevant. But it is exactly for these fire scenarios, and at early times, that the values of $\lambda_{\text {conv }}$ are relatively large. Furthermore, the most direct practical use for early time calculations would be for prediction of fire detector/sprinkler link response. It is exactly for such a purpose that the details of the convection problem ( $1 . e$. , the time-dependent temperature and velocity field of the ceiling jet) are likely to play an important role. 
For later times, when upper layer growth becomes a prominent feature of the enclosure environment, there is an indication in figures 4 and 5 of [2] that there may be a significant enhancement in values of $\lambda_{\text {conv }}$ over unconfined ceiling values. As indicated in the introduction, by using the procedures developed here together with ideas presented in [2] and [3], the next stage of this investigation will, hopefully, provide more definitive insight into this question.

\section{SUMMARY OF CONCLUSIONS AND FUTURE WORK}

The algorithm developed here was used to predict the response of a variety of realistic ceiling constructions to different fire scenarios. The algorithm is designed to be useful at times subsequent to ignition which are small enough (dependent on the size of the enclosure, and on the size and location of the fire) that the unconfined ceiling scenario of figure 1 is still relevant. Besides the specific results presented in the figures, the following is a summary of some general results which were indicated by the calculations.

Significant variations in ceiling response and lower target irradiation occur over intervals of radial distance from the fire of the order of $\mathrm{H}$.

Some quantitative similarity in ceiling response is obtained for constant $Q$ fire scenarios which have identical $Q_{\mathrm{H}}^{*}$. For such scenarios, and for a fairly wide range of $\mathrm{H}$, it appears that unconfined ceiling impingement point temperature response can be predicted with reasonable accuracy by specifying the single, dimensionless, fire strength parameter, $\mathrm{Q}_{\mathrm{H}}^{*}$. 
Convective heating along with radiative heating and cooling has a significant effect on the magnitude of the celling's lower surface temperature, and, as a result, on the magnitude of heat transfer by radiation from this surface to targets below.

Net convective heat transfer to enclosure ceilings can be a significant fraction of $Q$ at early times during growing fires. At later times, when an elevated temperature, upper smoke layer starts to fill an enclosed space, the situation in this regard is unclear. It will hopefully be clarified in the next stage of this investigation.

In general, the results of the calculations presented here are plausible, and they provide useful insight into the response of real ceilings to hazardous fires. Nevertheless, no data presently exist to compare theory with experiment. In this regard, a program at the National Bureau of Standards to measure ceiling response in reduced scale fire experiments has been recently initiated.

The next stage in this Investigation will use the algorithm of this paper in a new calculation procedure for estimating the ceiling response and firegenerated environment in expansive, but fully enclosed spaces. (If $D$ is the fire-to-wall distance in an enclosure fire, then, as discussed in [2], an expansive enclosure is one where $\mathrm{D} / \mathrm{H}$ is large enough that vigorous ceiling jet-wall interactions do not occur.) 


\section{ACKNOWLEDGMENTS}

The author gratefully acknowledges Mr. D. Stroup for his assistance in preparing the computer-generated plots. This work was supported by the U.S. Department of Health and Human Services, the Bureau of Mines and the National Park Service of the U.S. Department of Interior and the Federal Aviation Administration of the U.S. Department of Transportation.

\section{REFERENCES}

[1] Cooper, L.Y., Heat Transfer from a Buoyant Plume to an Unconfined Ceiling, J. Heat Transfer, 104, p. 446 (1982).

[2] Cooper, L.Y., Convective Heat Transfer to Cellings Above Enclosure Fires, 19th Symp. (Inter.) on Combustion, p. 933 (1982).

[3] Cooper, L.Y., A Buoyant Source in the Lower of Two, Homogeneous, Stably Stratified Layers, U.S. Nat'1 Bur. Standards, NBSIR 83-2789, (1983), and paper 83-WA/FE-4, 1983 Annua1 ASME Mtg., Boston.

[4] Yousef, W.W., Tarasuk, J.D., and McKeen, W.J., Free Convection Heat Transfer from Upward-Facing Isothermal, Horizontal Surfaces, J. Heat Transfer, 104, p. 493 (1982).

[5] Emmons, H.W., The Prediction of Fires in Buildings, 17th Symp. (Inter•) on Combustion, p. 1101 (1979).

[6] Mitler, H.E. and Emmons, H.W., Documentation for the Fifth Harvard Computer Fire Code, Home Fire Project Tech. Rpt. 45, Harvard Univ. (1981).

[7] Cooper, L.Y., A Mathematical Model for Estimating Available Safe Egress Time in Fires, Fire and Materials, 6, p. 135 (1982).

[8] NFPA 204M, Gulde for Smoke and Heat Venting, Nat'1. Fire Protection Assoc. (1982).

[9] Thomas, P.H. and Bullen, M.L., On the Role of kpC of Room Lining Materials in the Growth of Room Fires, Fire and Materials, 3, p. 68 (1979).

[10] Carslaw, H.S. and Jaeger, J.C., Conduction of Heat in Solids, Oxford, 2nd Ed. (1959). 


\section{NOMENCLATURE}

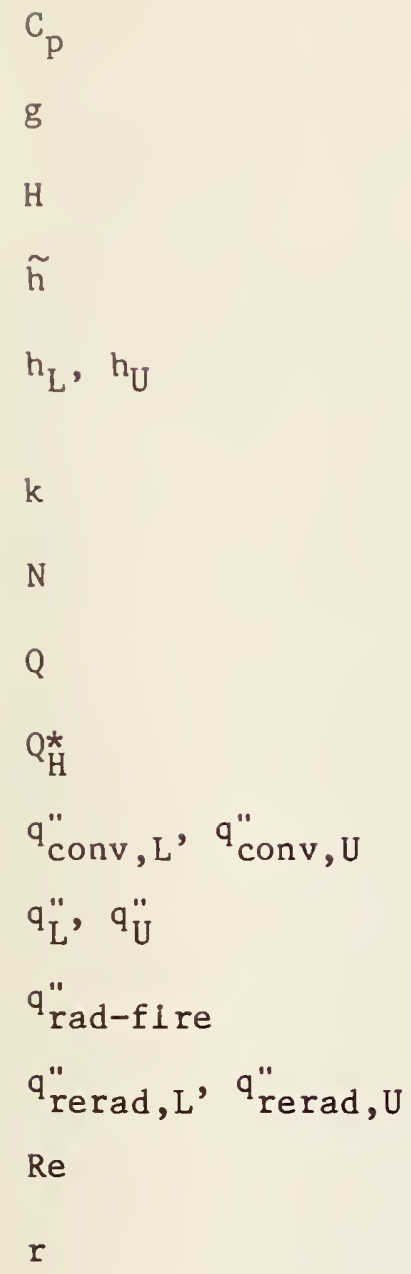

specific heat at constant pressure

acceleration of gravity

fire-to-ceiling distance

characteristic heat transfer coefficient

convective heat transfer coefficient at lower and upper surface

thermal conductivity

number of ceiling node points

fire's energy release rate

a dimensionless value of $Q$

convection from the lower and upper surface

net incident flux to lower and upper surface

direct radiation from the fire

net reradiation from the lower and upper surface

plume Reynold's number

radius from plume-ceiling impingment point

absolute temperature field of ceiling

ambient temperature

absolute temperature of lower and upper surface

time from ignition

indepth ceiling coordinate

thermal diffusivity

distance between node points in ceiling

emittance/absorptance of lower and upper grey surface

fraction of $Q$ radiated from fire

fraction of $Q$ convected to celling 
$\nu_{a m b}$

$\rho_{a m b}$

$\sigma$

ambient kinematic viscosity

ambient density

Stephan-Boltzmann constant 
Table 1. Decription of the four celling constructions

\begin{tabular}{|c|c|c|c|c|}
\hline Material & $\begin{array}{l}\text { Thickness } \\
\text { (m) } \\
\end{array}$ & $\begin{array}{c}k \\
\left(\mathrm{~m}^{-1}{ }^{-1} \mathrm{~K}^{-1}\right) \\
\end{array}$ & $\begin{array}{c}\alpha \\
\left(m^{2} s^{-1}\right) \\
\end{array}$ & Reference \\
\hline Fibre insulation board & 0.0127 & 0.04 & $1.2\left(10^{-7}\right)$ & [8] \\
\hline Gypsum board & 0.0127 & 0.134 & $1.577\left(10^{-7}\right)$ & [6] \\
\hline Concrete & 0.0508 & 0.92 & $4 \cdot 2\left(10^{-7}\right)$ & [8] \\
\hline Steel & 0.003175 & 46. & $120 \cdot\left(10^{-7}\right)$ & [9] \\
\hline
\end{tabular}


Table 2. Description of the six fire scenarios

\begin{tabular}{|c|c|c|c|c|}
\hline$H(m)=Q(k W)=$ & 101.2 & 1000. & 9883. & $\begin{array}{c}0.1054(t / s)^{2} \\
(t \text { ln seconds })\end{array}$ \\
\hline 2.0 & $x$ & $x$ & $x$ \\
\hline 5.0 & $Q_{\mathrm{H}}^{*}=0.01048$ & $Q_{\mathrm{H}}^{*}=0.1035$ & & $\mathrm{x}$ \\
\hline & & $\mathrm{x}$ & $\mathrm{x}$ & \\
\hline
\end{tabular}



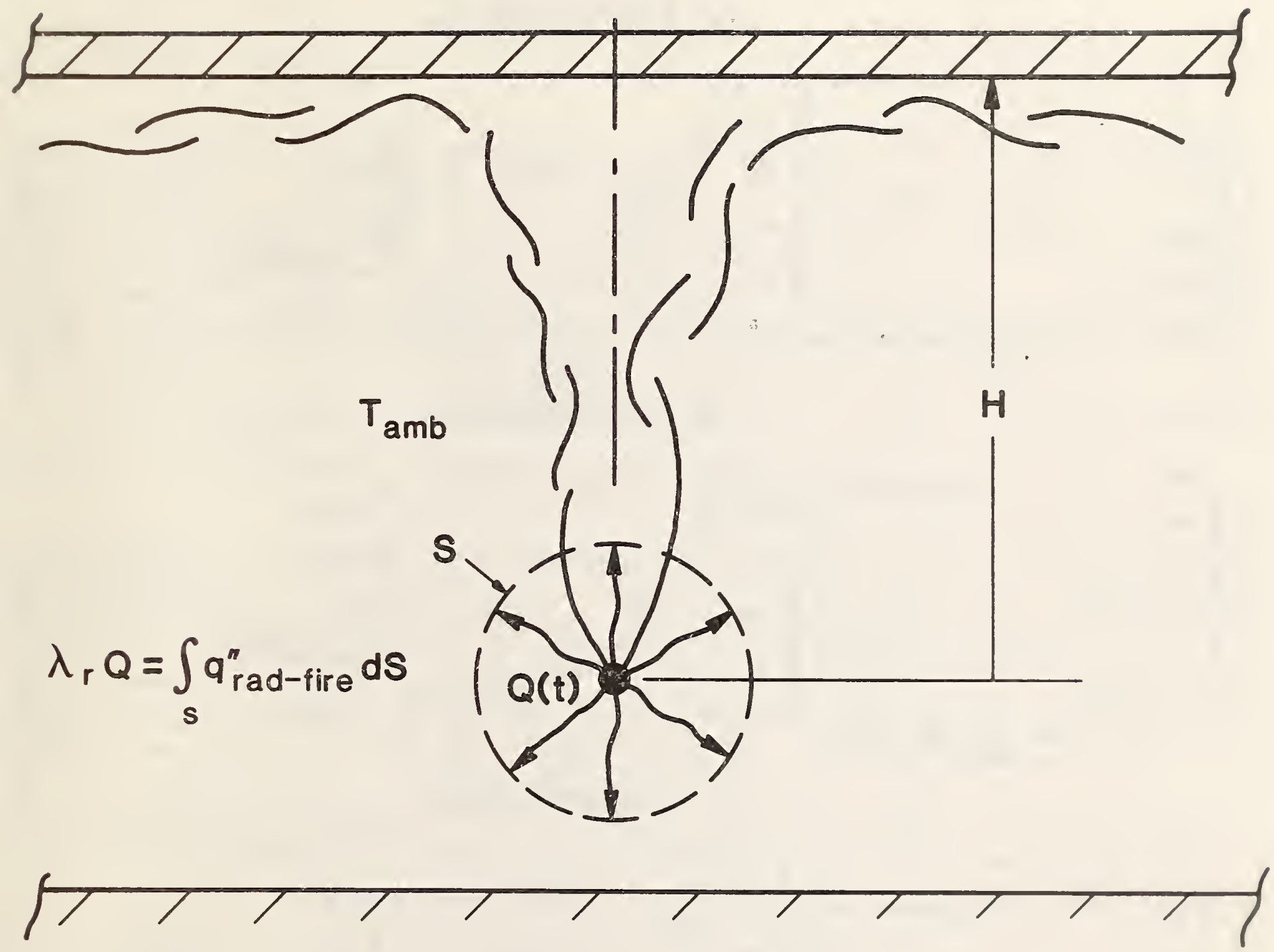

Figure 1. The unconfined celling fire scenario 

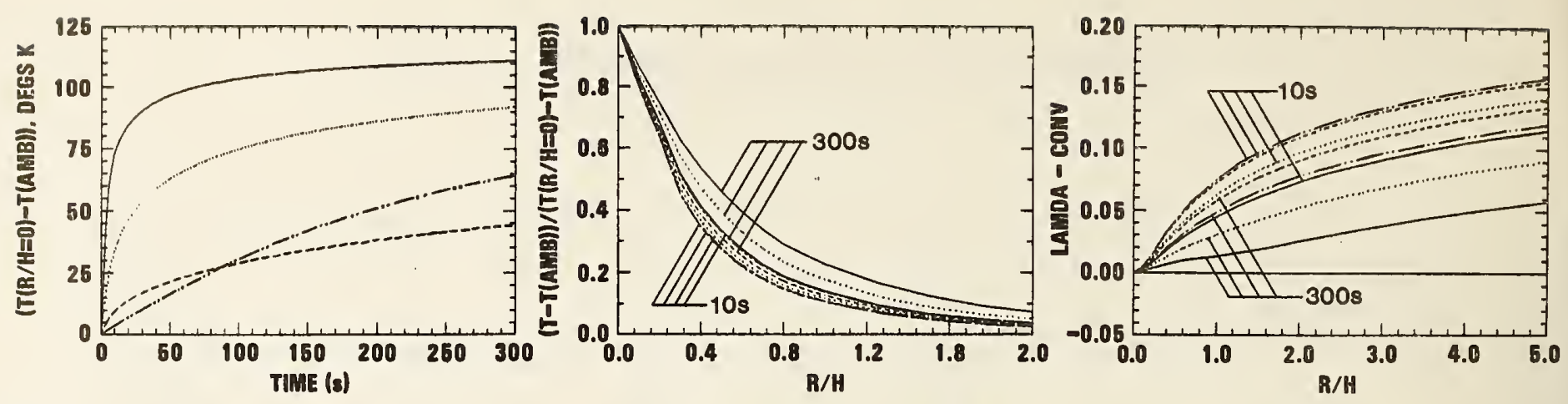

(a) $Q, H=101.2 \mathrm{~kW}, 2 \mathrm{~m}$;
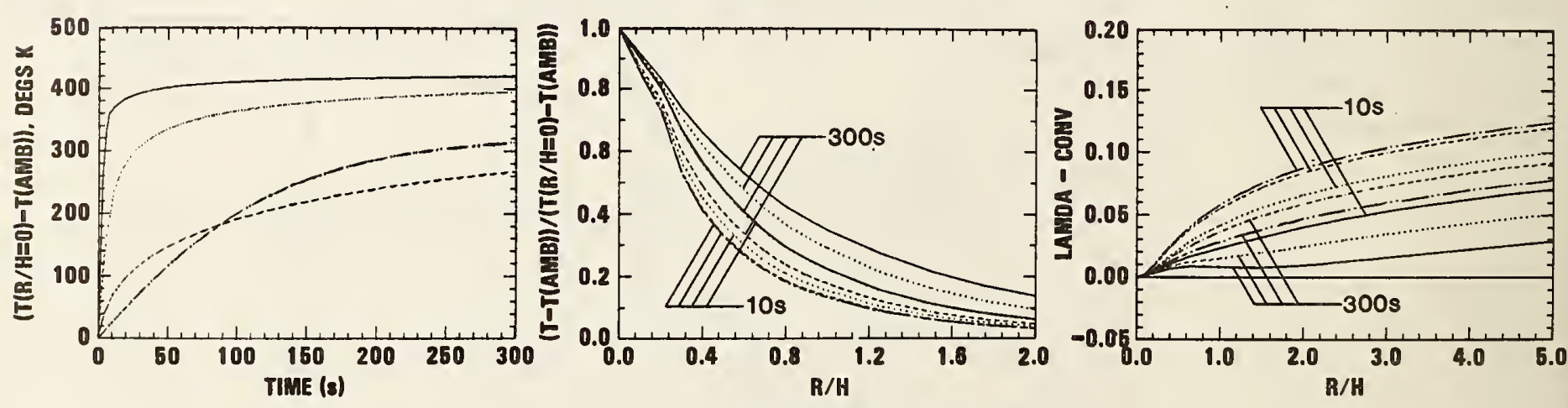

(b) $\mathrm{Q}, \mathrm{H}=1000 \mathrm{~kW}, 2 \mathrm{~m}$;
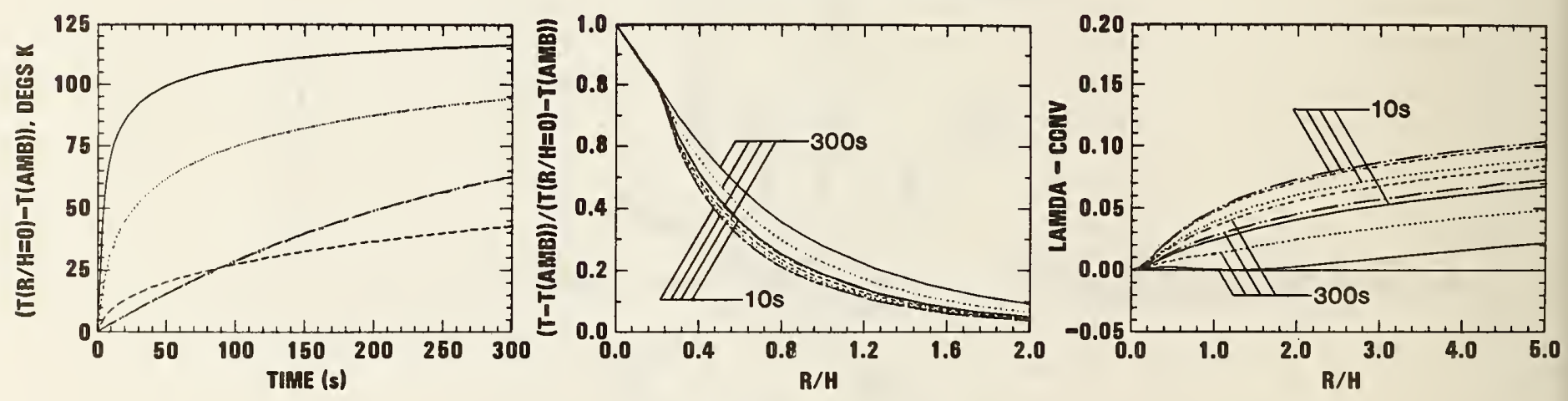

(c) $0, H=1000 \mathrm{~kW}, 5 \mathrm{~m}$;
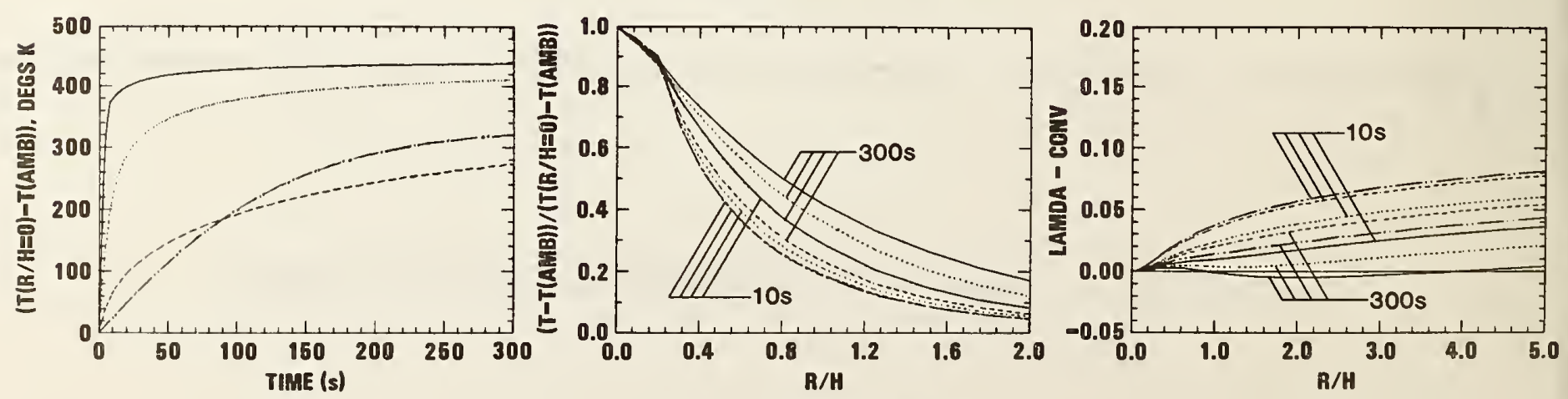

\section{(d) $0, \mathrm{H}=9883 \mathrm{~kW}, 5 \mathrm{~m}$;}

Figure 2. Responses of different ceiling constructions of Table 1 (insulation board gypsum board ...., concrete -..., steel ........) to fire scenarios of Table 2 

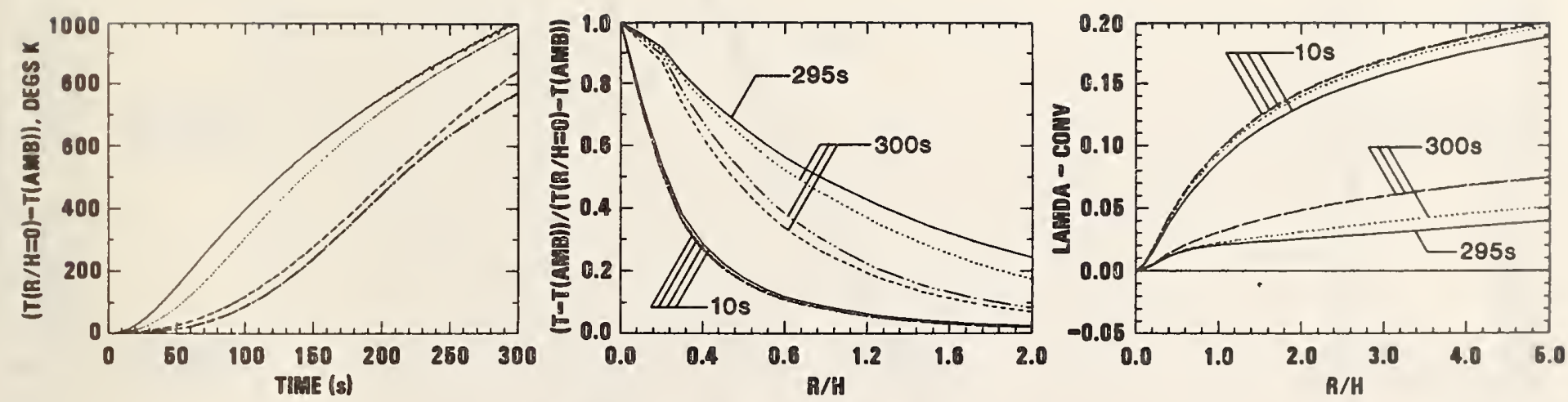

(e) $Q, H=0.1054 t^{2} \mathrm{~kW}, 2 \mathrm{~m}$ ( $t$ in seconds);
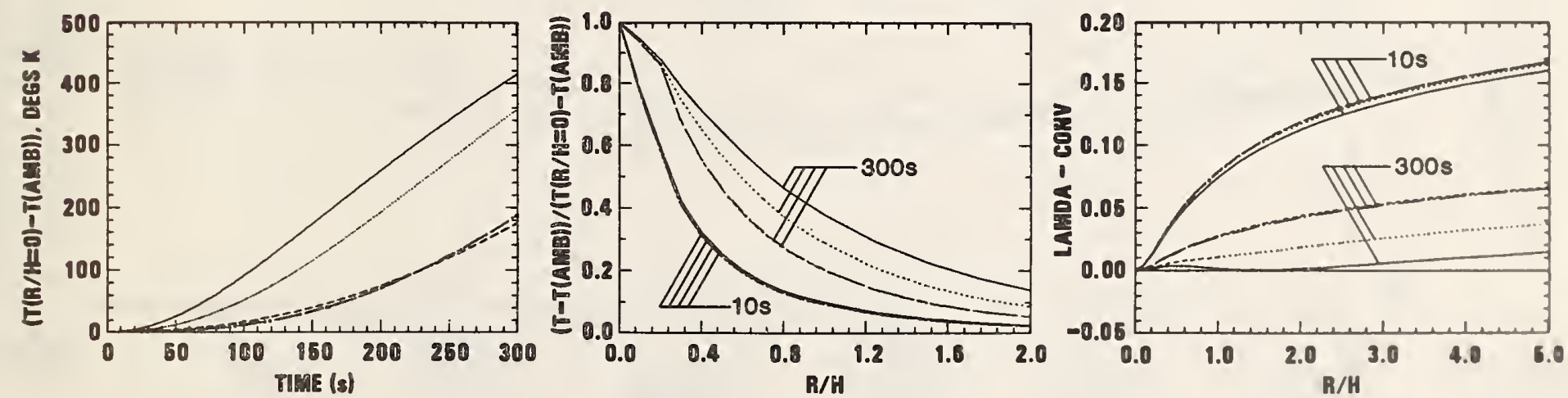

(f) $Q, H=0.1054 t^{2} k W, 5 \mathrm{~m}$ ( $t$ in seconds).

Figure 2. Responses of different ceiling constructions of Table I (insulations board (Cont'd.) gypsum board $\ldots$..., concrete ---, steel to fire scenarios of Table 2 


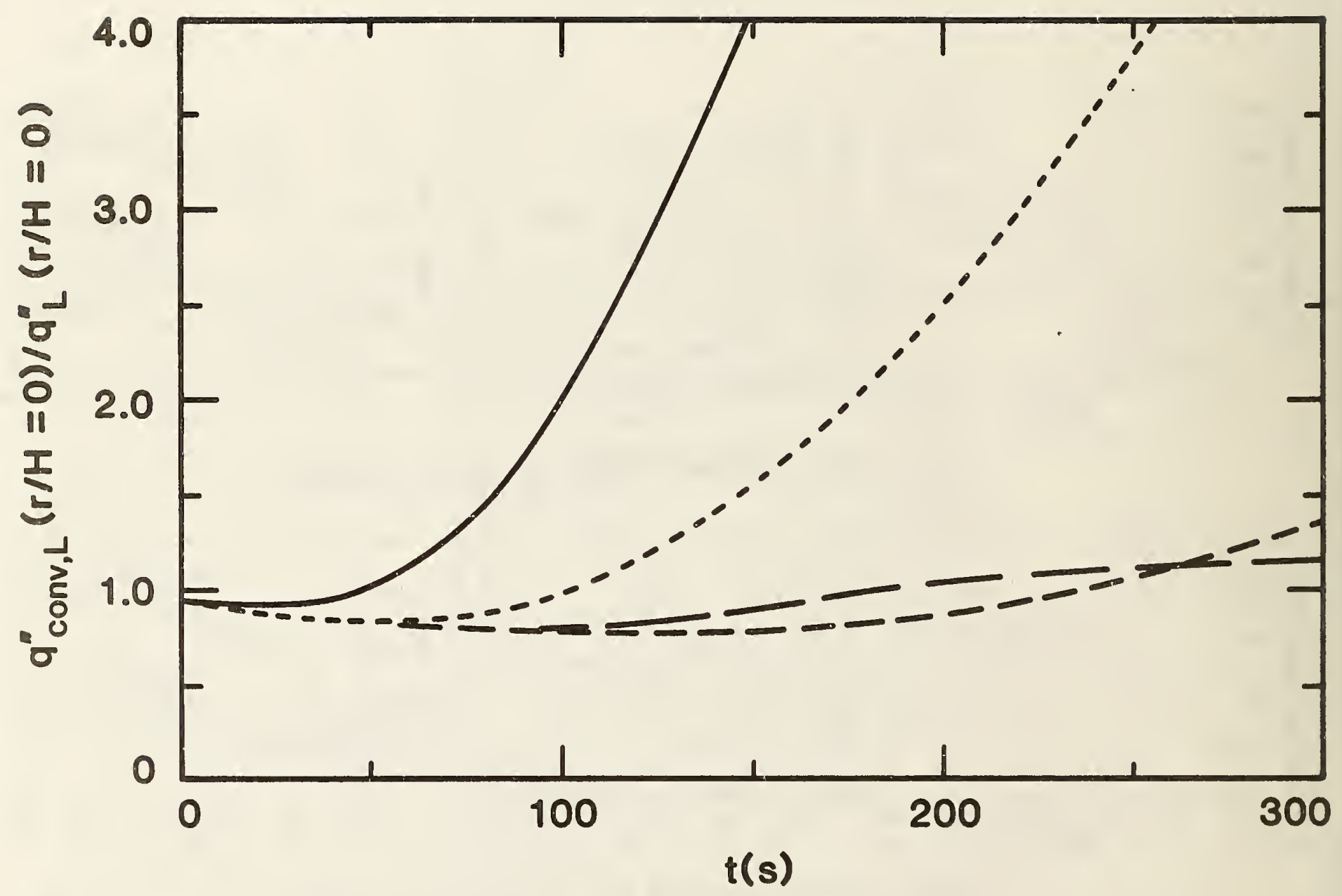

Figure 3. Plot of $q_{\text {conv }, L}^{\prime \prime}(r=0, t) / q_{L}^{\prime \prime}(r=0, t)$ for different celling constructions of Table 1 (see legend of Figure 2) to the fire scenario $Q, H=0.1054 t^{2} \mathrm{~kW}, 2 \mathrm{~m}$ ( $t$ in seconds) 


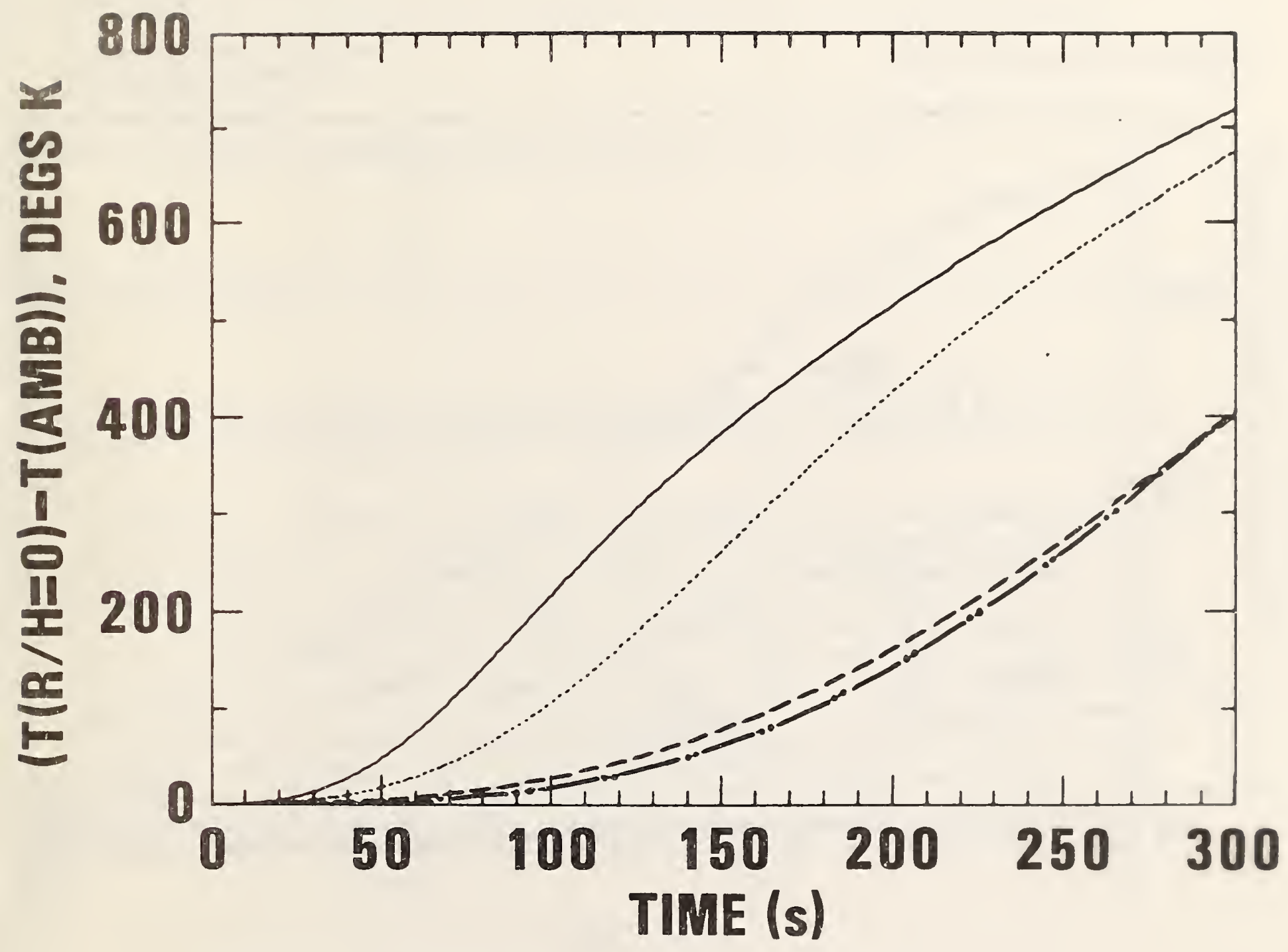

Figure 4. Plot of $T_{s, L}(r=0, t)-T_{a m b}$ for different celling constructions of Table 1 (see legend of Figure 2) to the flre scenario $Q, H=0.1054 t^{2} \mathrm{~kW}, 2 \mathrm{~m}$ with $q_{\text {conv }, L}=0$ ( $t$ in seconds) 


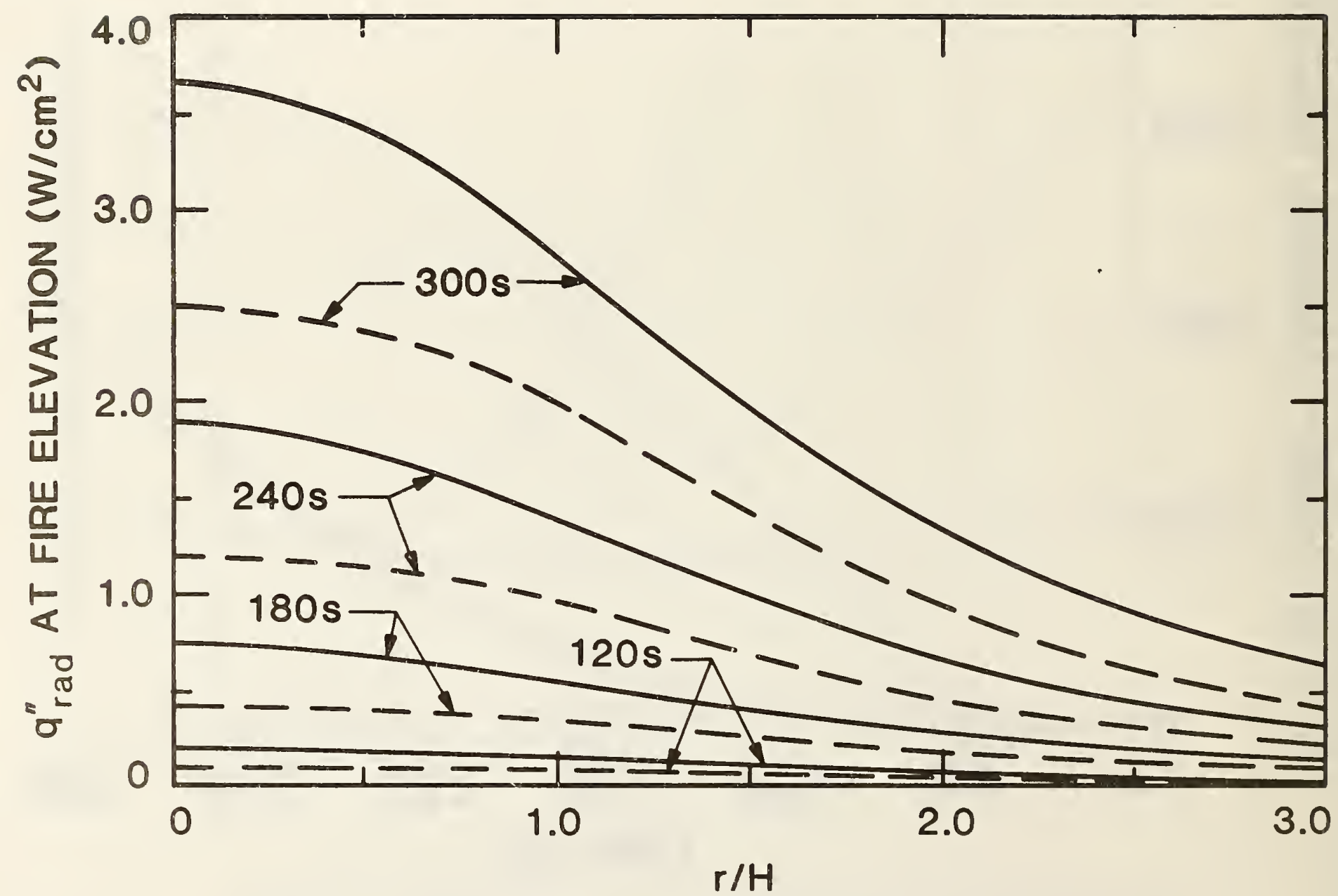

Figure 5. Plots of radiant flux to remote targets from the gypsum board ceiling responding to the fire scenario $Q, H=0.1054 t^{2} \mathrm{~kW}, 2 \mathrm{~m}$; nonzero $q_{\text {conv, }}^{\prime \prime}\left[\ldots, q_{\text {conv }, L}^{\prime \prime}=0 \ldots\right.$. ( $t$ in seconds) 
NBS.114A (REV. 2-BC)

U.S. DEPT. OF COMM.

1. PUBLICATION OR REPORT NO.

BIBLIOGRAPHIC DATA

SHEET (See instructions)

NBSIR 84-2856

2. Performing Organ. Report Nof 3. Publication Date

Apri1 1984

4. TITLE AND SUBTITLE

Thermal Response of Unconfined Ceilings Above Growing Fires and the Importance of Convective Heat Transfer

5. AUTHOR(S)

Leonard $Y$, cooper

6. PERFORMING ORGANIZATION (If joint or other than NBS, see instructions)

NATIONAL BUREAU OF STAMDARDS

DEPARTMENT OF COHMERCE

WASHINGTON, D.C. 20234

9. SPONSORING ORGANIZATIOHA AAAME AND COMPLETE ADDRESS (Strect, City, Stote, ZIF)

7. Contract Grant No.

8. Type of Report \& Period Covered

10. SUPPLEMENTARY NOTES

$\square$ Document describes a computer program; SF-185, FIPS Software Summary, is attached.

11. ABSTRACT (A 200-word or less factual summary of most significant information. If document includes a significant bibliography or literature survey. mention it here)

A procedure is developed to calculate the thermal response of unconfined ceilings above growing fires. The procedure uses an algorithm for conduction into the ceiling material. It takes account of heat transfer due to radiation from the combustion zone to the ceiling surface, and due to reradiation from the ceiling to the floor and furnishings. Finally, the procedure uses a previously developed algorithm for convective heat transfer to the ceiling from the fire-plume-driven ceiling jet. The procedure is used to predict radial-dependent surface temperature histories of typical ceiling materials under a variety of different realistic levels of hazardous fire energy generation rates and combustion zone-celling separation distances. The results give an indication of the influence of convective heat transfer on peak ceiling thermal response, losses from fire plume gases, and radial variations and peak values of ceiling-to-floor irradiation during enclosure fires.

12. KEY WORDS (Six to twelve entries; alphabetical order; capitalize only proper names; and separate key words by semicolon s) ceilings; compartment fires; fire plumes; heat transfer; room fires

13. AVAILABILITY

[X] Unlimited

For Official Distribution. Do Not Release to NTIS

$\square$ Order From Superintendent of Documents, U.S. Government Printing Office, Washington, D.C. 20402.

14. NO. OF PRINTED PAGES

36

15. Price

X. Order From National Technical Information Service (NTIS), Springfield, VA, 22161 

